\title{
The Attenuation of Idiosyncratic Risk under Alternative Portfolio Weighting Strategies: Recent Evidence from the UK Equity Market
}

\author{
Chia Rui Ming Daryl ${ }^{1} \&$ Lim Kai Jie Shawn ${ }^{2}$ \\ ${ }^{1}$ Department of Statistics, University of Warwick, Coventry, United Kingdom \\ ${ }^{2}$ Department of Economics, University College London, London, United Kingdom \\ Correspondence: Chia Rui Ming Daryl, Department of Statistics, University of Warwick, Coventry, CV4 7ES, \\ United Kingdom. Tel: 44-792-806-5816. E-mail: r.m.d.chia@warwick.ac.uk
}

Received: August 13, 2012

Accepted: September 11, 2012

Online Published: September 20, 2012

doi:10.5539/ijef.v4n11p1

URL: http://dx.doi.org/10.5539/ijef.v4n11p1

\begin{abstract}
In this study, we investigate the attenuation of idiosyncratic risk and corresponding benefits of diversification for equally weighted and market capitalisation weighted portfolios in the UK Equity Market over 2002 - 2012. We analyse the absolute benefits of risk reduction by testing the homogeneity of variances of portfolios of different sizes using Levene's Test. Next, we perform a cost-benefit analysis to determine the return benefit of diversification from a practical perspective. We find that the absolute benefits of diversification for an equally weighted portfolio are greater in the 'crisis' than 'pre-crisis' period, but when we analyse the results from a practical perspective the benefits fall dramatically and the results are reversed. When comparing the benefits of market capitalisation weighted and equally weighted portfolios, we note that the benefits of diversification tend to be greater for an equally weighted portfolio for small portfolios but that a crossover occurs as the size of the portfolio increases. The relative benefits of diversification under these different weighting strategies are thus highly dependent upon the state of the market and further study is needed to determine why the diversification benefits for the alternative weighting strategies decay at varying rates.
\end{abstract}

Keywords: portfolio diversification, idiosyncratic risk, index funds, weighting methodology

JEL Classification: C15, G01, G11, G17

\section{Introduction}

The benefits of employing a portfolio approach to investing plays a central role within modern finance theory. The arguments for this approach has its roots in the seminal paper by Markowitz (1957) that laid the theoretical framework for what has now evolved to become Modern Portfolio Theory. One key implication and oft quoted result from this theory is that increasing the size of one's portfolio helps to reduce idiosyncratic risk, and it is hence possible to achieve superior risk-adjusted performance through the use of a portfolio approach to investing. However, what is the optimal number of securities that one should hold to reap the maximum benefits of diversification?

This is a key question that academics grappled with in the wake of Modern Portfolio Theory. The early literature looked at the issue from 2 different perspectives. The first approach investigates the benefits of diversification by analysing the results from the simulation of numerous random portfolios and is credited to the early work of Evans and Archer (1968). The second approach seeks to find an exact solution to quantify the benefits of diversification and is credited to the analytical approach first espoused by Elton and Gruber (1977). While the ability to mathematically quantify the benefits of diversification in an exact manner is intuitively appealing, it comes at the cost of over simplification as it employs the use of many assumptions to reduce the problem to something that is mathematically tractable but not necessarily operationally useful. Hence, we have adopted a methodology in line with the first approach as it gives us greater flexibility in the crafting of our methodology and yields results that will be of interest to both academics and practitioners.

In this paper, we investigate the benefits of diversification in the UK equity market through the use of a modified methodology that incorporates elements from both of these approaches. In addition, we present a more realistic model of diversification by constructing market capitalisation weighted portfolios in addition to equally-weighted portfolios that are traditionally the focus of studies on diversification. 


\section{Background}

\subsection{Objectives and Significance of Paper}

While the study of the benefits of diversification is by no means a novel topic, we propose to contribute to existing literature by suggesting improvements on the best way to quantify it. In this paper, we employ 3 changes that we believe allows us to add to the existing literature on the topic.

Firstly, we conduct the experiment on the UK Equity Market using the FTSE All-Share Index as a benchmark and present the empirical results for diversification on a previously untested market over a recent time period.

Next, while many studies have adopted an ex-ante approach to their investigation, we have adopted an ex-post approach in this study. Instead of asking the question what are the likely benefits in the future, we have asked the question what were the benefits during the 'pre-crisis' and 'crisis' period. This allows us to present empirical results on how the benefits from diversification and optimal number of securities to hold to reap that benefit may have changed during a period of high volatility and market uncertainty.

Finally, we consider an alternative weighting scheme that allows for results that are more realistic and representative. While the traditional approach looks at equally weighted portfolios, we include in our analysis the benefits from diversification of both an equally weighted portfolio and a market capitalisation weighted portfolio. Studying the benefits of diversification for a market capitalisation weighted portfolio is more appropriate as the de facto benchmark for full diversification with the lowest possible cost would be that offered by an Exchange-Traded Index Fund, which tends to be a market capitalisation weighted investment vehicle In addition, the market capitalisation weighted portfolio is a better resemblance of a mean-variance efficient portfolio than an equally weighted one and more reflective of an approach that might be employed in practice. Hence, if we compare the cost of full diversification using an ETF with an equally weighted portfolio or use an alternative benchmark such as a mutual fund we would overstate the cost of diversification and hence lead to a misleading conclusion not representative of the decisions that would be made in reality.

\subsection{Traditional Approaches to Testing the Benefits of Diversification}

There are 2 general approaches that have been employed in tests on diversification using simulated portfolios. The first approach pioneered by Evans and Archer (1968) focuses on the absolute benefits of diversification. This approach attempts to find the level beyond which holding more securities in a portfolio has a negligible impact on the reduction of risk. Statistical tests such as the T-Test and F-Test are often employed in these types of studies to find the point at which increasing the size of a portfolio no longer has a statistically significant impact on the reduction of risk as well as the level at which standard deviation tends to converge, or the asymptote for the graph of portfolio size vs. standard deviation. This approach has also been adopted by a number of contemporary studies on diversification and is the methodology often referenced in finance textbooks (Newbould \& Poon, 1993, 1996). Lai and Seiler (2001) use this methodology to study diversification within industry groups and Benjelloun (2010) uses this approach to study the benefits of diversification from a terminal wealth perspective.

The second approach pioneered by Statman $(1987,2004)$ takes a more practical view of the issue and seeks to find the number of securities beyond which the benefits of diversification are lower than the holding costs from an increased number of securities. This approach converts the risk of a simulated portfolio of $n$ securities into a comparable return figure by combining the simulated portfolio with a risk-free asset to generate portfolio combinations with the same level of risk. The cost of a collective investment scheme such as a mutual fund or exchange traded fund is often used as a proxy for the cost of full diversification and is compared to the return benefit from increasing the number of securities held to obtain the optimal number of securities that one should hold in a well-diversified portfolio. This approach has also been used to study the benefits of diversification in other asset classes and markets. Gupta and Khoon (2001) adopt this approach to study the number of securities needed to form a diversified portfolio in Malaysia while Lee (2005) studies the benefits of diversification in commercial real estate portfolios.

In this study, we employ both of these approaches to present the benefits of diversification from both an absolute and practical perspective. We use these approaches on equally weighted random portfolios as employed in the original methodologies and extend that methodology to test the benefits of diversification using market capitalisation weighted random portfolios.

\subsection{Time Period of Investigation}

The time period employed is likely to have a material impact on the benefits of diversification. For this paper, we split our analysis into 2 time period, a 5 year period from 1 July 2002 to 30 June 2007 that we have called the 
'pre-crisis period' and a 5 year period from 1 July 2007 to 30 June 2012 that we have called the 'crisis period'. By using these 2 particular periods in time, we hope to present results on the benefits of diversification during a normal period of time and during a period of crisis, as well as provide a comparison on how the optimal number of securities to hold from a diversification perspective might have changed during this period of market stress.

\subsection{Weighting Strategies}

The manner in which portfolios are constructed will have a tangible impact on the risk and return profile of the portfolio. In particular, alternative weighting strategies are likely to have a material influence on the risk and return characteristics of a portfolio and hence the effectiveness of a diversification strategy. In this study we consider 2 alternative weighting strategies, equally weighted portfolios and market capitalisation weighted portfolios.

An equally weighted portfolio refers to a construction technique in which an equal dollar amount is invested in each holding, regardless of any differences in the fundamental characteristics of component securities. When applied to a large universe of stocks of different sizes such as in our study of the FTSE all-share index, the return profile of such portfolios will inevitably have an implicit tilt towards stocks with a small market capitalisation and may not be reflective of a portfolio that can be achieved in reality. However, equally weighted portfolios have traditionally been the focus of diversification studies as it is computationally easier to work with equally weighted portfolios when employing analytical approaches. As we are conducting our analysis using a simulation approach instead of an analytical one, the added complexity of portfolios with unequal weights is of a smaller concern. Beyond the fundamental tilt of an equally weighted portfolio, the larger problem of such a weighting strategy is the lack of a representative low-cost benchmark for full diversification. Furthermore, the correlation between stocks with a small market capitalisation and stocks with a large market capitalisation compared to stocks with similar market capitalisation tends to be lower (Huang, Eun \& Lai, 2006), thus when combined into a portfolio this will exhibit lower levels of standard deviation. Hence, using an equally weighted portfolio is likely to overstate the benefits of diversification and present conclusions that may not be operationally meaningful.

In order to address some of these problems, we have considered an alternative weighting strategy, that of a market capitalisation weighted portfolio. When constructing market capitalisation weighted portfolios, the proportion of each security held is according to the size of its market capitalisation. The benefit of this approach is that our benchmark, the FTSE All-Share index is by construction a capitalisation-weighted index and hence there are viable low cost options for full diversification based on the index. Results based on market capitalisation weighted portfolios are closer to the type of decisions made in reality and are likely to have more meaningful operational implications.

\section{Methodology}

\subsection{Creating Random Portfolios of $n$ Securities by Simulation}

The aim of this study is to investigate the empirical benefits of diversification by increasing the number of securities held in a portfolio under alternative weighting strategies. In the first step of this process, we create random portfolios of $n$ securities by simulation. The $n$ securities are selected at random based on a uniform distribution.

For each run, we calculated the daily return of the portfolio at time $i\left(R_{i}^{d}\right)$ with the following equations.

For equally weighted portfolios:

$$
R_{i}^{d}=\frac{1}{n} \sum_{k=1}^{n} R_{i}^{k}
$$

For $n=1$ to 250

Where $n$ is the number of securities in the portfolio.

For market capitalisation weighted portfolios:

$$
\begin{gathered}
R_{i}^{d}=\sum_{k=1}^{n} w_{k} R_{i}^{k} \\
w_{k}=\frac{m_{k}}{\sum_{k=1}^{n} m_{k}}
\end{gathered}
$$


Where

$w_{k} \quad$ : Weight of security $k$ in the $n$ security portfolio

$m_{k}$ : Market capitalisation of security $k$ at the start of the time period.

We also calculate the geometric mean return for the entire period considered $\left(R_{p}\right)$ using the following equation:

$$
R_{p}=\exp \left(\frac{1}{L} \sum_{i=1}^{n} \log _{e} R_{i}^{d}\right)
$$

For $L=1265$ for pre-crisis and $L=1262$ for crisis, where $L$ is the number of daily return data points.

Finally, the portfolio standard deviation $\left(s_{p}\right)$ is computed:

$$
S_{p}=\sqrt{\frac{1}{L-1} \sum_{i=1}^{L}\left(\log _{e} R_{p}-\log _{e} R_{d}^{i}\right)^{2}}
$$

We conduct 20,000 runs for each portfolio of size $n$ for each of the 2 time periods (10,000 runs for equally weighted portfolios and 10,000 runs for market capitalisation weighted portfolios), which yields a total of $10,000,000$ simulated portfolios. To increase the robustness of our results, the simulations were run with replacement.

\subsection{Absolute Benefits of Diversification}

In this section, we evaluate the absolute benefits of diversification by finding the level at which further increases in the number of securities held in a portfolio does not lead to a reduction in variance that is statistically significant. The traditional approach employed for tests of the homogeneity of variance between 2 samples, in this case portfolios with a different number of securities, is the F-Test. However, the F-Test has been shown to be extremely sensitive to the normality assumption (Box, 1953; C. Markowski \& E. Markowski, 1990) while financial data series often exhibit characteristics that are not consistent with a normal distribution. An alternative test, Levene's test (Levene, 1960), uses the average of the absolute deviations instead of the mean square of deviations and this adjustment makes the test criterion much less sensitive to non-normal distributions (Snedecor and Cochran, 1976). Hence, we employ Levene's Test instead to test the equality of variances between successive portfolios. The results from this test are reported in Table 3.

\subsubsection{Levene's Test}

We conduct Levene's Test on successive portfolios with different numbers of securities. The test is conducted with the following hypotheses:

$H_{0}$ : The 2 samples have the same variance

$H_{1}$ : The 2 samples have different variances

The test statistic, $W$, is defined as follows:

$$
\begin{gathered}
W=\frac{N-k}{k-1} \frac{\sum_{n=1}^{k} N_{n}\left(Z_{n .}-Z_{. .}\right)^{2}}{\sum_{n=1}^{k} \Sigma_{j=1}^{N_{i}}\left(Z_{n j}-Z_{n .}\right)^{2}} \\
Z_{n j}=\left|Y_{n j}-\overline{Y_{n .}}\right| \\
Z_{n \cdot}=\frac{1}{N_{i}} \sum_{j=1}^{N_{i}} Z_{n j} \\
Z_{. .}=\frac{1}{N} \sum_{n=1}^{k} \sum_{j=1}^{N_{i}} Z_{n j}
\end{gathered}
$$

Where

$$
\begin{array}{ll}
W & : \text { Test statistic } \\
k & : \text { Number of groups to which the samples belong } \\
N & : \text { Total number of runs } \\
N_{i} & \text { : Number of runs in the n-security portfolio simulation }
\end{array}
$$


$Y_{n j}:$ Value of the $\mathrm{j}$-th run from the n-security portfolio simulation

$\overline{Y_{l}}$. : Mean for the n-security portfolio simulation

The significance of $W$ is tested against $\mathrm{F}(0.05,1,19998)$ where $\mathrm{F}$ is a quantile of the F-test distribution. We conduct this test for portfolios of successive sizes to determine the number of securities that must be added to each portfolio of $n$ securities such that there is a statistically significant change in variance and hence benefit to diversification.

\subsection{Cost-benefit Analysis}

While measuring the absolute benefit of diversification is important, such an approach does not take into account the fact that holding more securities comes with an added cost as well. In reality the decision of how many securities to hold is likely to be contingent upon some form of cost-benefit analysis, where the number of securities held will be increased up until the point where the marginal benefit of diversification exceeds the marginal cost of holding more securities. In this section, we approach the issue of diversification form a more practical perspective by making that explicit cost-benefit analysis.

\subsubsection{Measuring the Benefit of Full Diversification}

We quantify the benefit of fully diversifying each $n$-security portfolio to the index portfolio by converting the associated reduction in standard deviation into a return figure. This is done by levering down all $n$-security portfolios such that its standard deviation is equal to that of the $m$-security population portfolio.

In effect, the process transforms all $n$-security portfolios into ones where a portion $\sigma_{m} / \sigma_{p(n)}$ of the portfolio remains invested in $n$-securities, while the remaining $\left(1-\sigma_{m} / \sigma_{p(n)}\right)$ is invested at the risk free rate. The net result is that the levered down portfolios will have a standard deviation equal to that of the $m$-security population portfolio. With all portfolios having the same standard deviation, differences in returns can therefore be attributed to diversification effects.

The benefit from diversification is calculated using the following equation:

$$
D_{p(n)}=R_{m}-\left[\left(R_{p(n)}-R_{f}\right) \frac{\sigma_{p(n)}}{\sigma_{m}}+R_{f}\right]
$$

Where

$D_{p(n)} \quad$ : return benefit of diversifying an $\mathrm{n}$-stock portfolio to an $\mathrm{m}=498$ stock portfolio

$R_{p(n)} \quad$ : geometric mean return of the n-stock portfolio

$R_{m} \quad$ : geometric mean return of the index portfolio

$R_{f} \quad$ : risk free rate obtained from rolling 3 month government bills over each 5 year period

$\sigma_{p(n)} \quad:$ standard deviation of returns of the n-stock portfolio

$\sigma_{m}$ : standard deviation of returns of the population of $\mathrm{m}=498$ stocks

We first deduct the relevant risk free rate from each $n$-security portfolio's geometric mean return to find its market risk premium, $R_{p(n)}-R_{f}$. This risk premium is then multiplied by the ratio of the M-security population standard deviation to the $n$-security portfolio standard deviation, $\sigma_{m} / \sigma_{p(n)}$, in order to lever down the portfolios' risk premium. The risk free rate is then added back to the market risk premium of each levered down portfolio. Finally, the difference between the $m$-security population portfolio return and the last calculated figure is the benefit from full diversification.

All values above are annualised and $D_{p(n)}$ is calculated for $n$ ranging from 1 to 250 .

Digressing slightly from explaining the above calculation, it is of significance that the relevant risks free rate in this study is that of the annualised 5 year internal rate of return obtained by rolling 1-year UK governments securities over each 4 year period under study. Such is consistent with minimising the price and reinvestment risk present in longer dated generic government rates, and is consistent with the interpretation of the risk free rate in modern literature (Mukherji, 2011; Damodaran, 2010).

\subsubsection{Measuring the Cost of Full Diversification}

Diversifying fully from an $n$-security portfolio to an $m$-security portfolio incurs a cost equal to the difference in cost between holding each of the above portfolios. Given the simple, one-time transaction buy-and-hold strategy of constructing each $n$-security portfolio, price spread costs are negligible when spread over the entire 5 year 
period. Further, transaction fees are negligible vis-à-vis returns in our study given institutional-sized portfolios. We hence assume that the cost of constructing and holding the $n$-security portfolio is zero.

This leaves us with the cost of full diversification being equal to the cost of holding the $m$-security population portfolio. Much like existing literature (Statman, 1987), we take the total expense ratio of a representative ETF as a proxy for the cost of constructing and maintaining the said $m$-security population portfolio.

The cost of full diversification is hence the total expense ratio of a representative ETF, and in this case, the relevant ETFs - db x-trackers FTSE All-Share and the Lyxor ETF FTSE All Share ETFs - both have an expense ratio of $0.40 \%$. This will be the cost of full diversification in our study.

Finally, we find the values of $n$ for each period and weighting methodology that best equates the benefit of full diversification with its cost - such is the point at which the marginal benefit of diversification is outweighed by the cost.

\section{Results}

\subsection{Data}

Daily closing price and market capitalisation data were extracted from the Bloomberg Professional service for each of the FTSE All-Share Index's constituents. In order to best reflect the ex-post return and volatility experienced by a buy-and-hold investor over each of the two periods under study, price data was extracted for the equities that constituted the index on each of the period's start date. The relevant market capitalisation weights used in constructing the market-cap weighted portfolio were then those on each period's start date, reflecting the proportions of each stock an investor will include in a market-cap weighted portfolio constructed at the beginning of each period.

Also in line with ensuring representativeness of a buy-and-hold portfolio investment, daily price data was adjusted for normal cash dividends (regular cash, interim, income, estimated, partnership distribution, final, interest on capital, distributed and prorated), abnormal cash dividends (special cash, liquidation, capital gains, memorial, return of capital, rights redemptions, return premium, preferred rights redemption, proceeds/rights, proceeds/shares, proceeds/warrants) and capital changes (spin-offs, stocks splits/consolidations, stock dividend/bonus, rights offerings/entitlement).

The price data was then screened for equities which lacked a complete dataset over each five year period under study. These equities were removed from the dataset. Eventually, what remained were 498 equities out of 703 and 698 index constituents for the pre-crisis and crisis periods respectively. These 498 equities were then inputs into our portfolio simulations for both periods.

\subsection{Simulation Summary}

Table 1 below displays the portfolio standard deviations for both the pre-crisis and crisis period for an equally weighted and market capitalisation weighted portfolio of $n$ equities, with $n$ ranging from 1 to 250 and $n=498$ representing the population of equities under consideration, which is a proxy for all the constituents in the FTSE All-Share Index. While we are using the model generated standard deviation figures for all $n$ between 1 and 250, for the interest of brevity, only steps of 10 are displayed beyond $n=50$. 
Table 1. Annualised Daily Standard Deviation of Returns

\begin{tabular}{|c|c|c|c|c|c|c|c|c|c|}
\hline \multirow[b]{2}{*}{$\begin{array}{l}\text { Portfolio } \\
\text { Size }(n)\end{array}$} & \multicolumn{2}{|c|}{$\begin{array}{c}\text { Pre-Crisis Period } \\
\text { 1 July } 2002 \text { to } 30 \text { June } \\
2007 \\
\end{array}$} & \multicolumn{2}{|c|}{$\begin{array}{c}\text { Crisis Period } \\
\text { 1 July } 2007 \text { to } 30 \text { June } \\
2012 \\
\end{array}$} & & \multicolumn{2}{|c|}{$\begin{array}{c}\text { Pre-Crisis Period } \\
\text { 1 July } 2002 \text { to } 30 \text { June } \\
2007\end{array}$} & \multicolumn{2}{|c|}{$\begin{array}{c}\text { Crisis Period } \\
1 \text { July } 2007 \text { to } 30 \text { June } \\
2012 \\
\end{array}$} \\
\hline & $\begin{array}{c}\text { Equally } \\
\text { Weighted } \\
\text { Portfolio }\end{array}$ & $\begin{array}{c}\text { Market-Cap } \\
\text { Weighted } \\
\text { Portfolio } \\
\end{array}$ & $\begin{array}{c}\text { Equally } \\
\text { Weighted } \\
\text { Portfolio }\end{array}$ & $\begin{array}{c}\text { Market-Cap } \\
\text { Weighted } \\
\text { Portfolio } \\
\end{array}$ & $\begin{array}{l}\text { Portfolio } \\
\text { Size }(n)\end{array}$ & $\begin{array}{c}\text { Equally } \\
\text { Weighted } \\
\text { Portfolio }\end{array}$ & $\begin{array}{l}\text { Market-Cap } \\
\text { Weighted } \\
\text { Portfolio }\end{array}$ & $\begin{array}{c}\text { Equally } \\
\text { Weighted } \\
\text { Portfolio }\end{array}$ & $\begin{array}{c}\text { Market-Cap } \\
\text { Weighted } \\
\text { Portfolio } \\
\end{array}$ \\
\hline 1 & $30.195 \%$ & $30.195 \%$ & $42.673 \%$ & $42.662 \%$ & 37 & $11.845 \%$ & $18.137 \%$ & $20.917 \%$ & $30.000 \%$ \\
\hline 2 & $22.652 \%$ & $25.117 \%$ & $34.038 \%$ & $37.967 \%$ & 38 & $11.818 \%$ & $18.101 \%$ & $20.890 \%$ & $29.946 \%$ \\
\hline 3 & $19.696 \%$ & $23.274 \%$ & $30.291 \%$ & $35.926 \%$ & 39 & $11.793 \%$ & $18.076 \%$ & $20.865 \%$ & $29.887 \%$ \\
\hline 4 & $17.953 \%$ & $22.288 \%$ & $28.129 \%$ & $34.768 \%$ & 40 & $11.771 \%$ & $18.048 \%$ & $20.840 \%$ & $29.833 \%$ \\
\hline 5 & $16.825 \%$ & $21.590 \%$ & $26.734 \%$ & $34.010 \%$ & 41 & $11.746 \%$ & $18.014 \%$ & $20.816 \%$ & $29.783 \%$ \\
\hline 6 & $16.027 \%$ & $21.142 \%$ & $25.741 \%$ & $33.422 \%$ & 42 & $11.725 \%$ & $17.982 \%$ & $20.791 \%$ & $29.748 \%$ \\
\hline 7 & $15.410 \%$ & $20.785 \%$ & $24.993 \%$ & $33.084 \%$ & 43 & $11.705 \%$ & $17.957 \%$ & $20.767 \%$ & $29.696 \%$ \\
\hline 8 & $14.932 \%$ & $20.503 \%$ & $24.410 \%$ & $32.748 \%$ & 44 & $11.684 \%$ & $17.924 \%$ & $20.744 \%$ & $29.674 \%$ \\
\hline 9 & $14.543 \%$ & $20.247 \%$ & $23.968 \%$ & $32.493 \%$ & 45 & $11.667 \%$ & $17.902 \%$ & $20.723 \%$ & $29.613 \%$ \\
\hline 10 & $14.216 \%$ & $20.041 \%$ & $23.592 \%$ & $32.265 \%$ & 46 & $11.649 \%$ & $17.874 \%$ & $20.703 \%$ & $29.570 \%$ \\
\hline 11 & $13.946 \%$ & $19.873 \%$ & $23.280 \%$ & $32.134 \%$ & 47 & $11.631 \%$ & $17.845 \%$ & $20.686 \%$ & $29.532 \%$ \\
\hline 12 & $13.722 \%$ & $19.727 \%$ & $23.021 \%$ & $32.070 \%$ & 48 & $11.616 \%$ & $17.820 \%$ & $20.667 \%$ & $29.500 \%$ \\
\hline 13 & $13.519 \%$ & $19.588 \%$ & $22.795 \%$ & $31.951 \%$ & 49 & $11.601 \%$ & $17.798 \%$ & $20.648 \%$ & $29.465 \%$ \\
\hline 14 & $13.343 \%$ & $19.465 \%$ & $22.607 \%$ & $31.805 \%$ & 50 & $11.585 \%$ & $17.777 \%$ & $20.630 \%$ & $29.429 \%$ \\
\hline 15 & $13.193 \%$ & $19.360 \%$ & $22.432 \%$ & $31.656 \%$ & 60 & $11.460 \%$ & $17.585 \%$ & $20.499 \%$ & $29.108 \%$ \\
\hline 16 & $13.058 \%$ & $19.241 \%$ & $22.271 \%$ & $31.568 \%$ & 70 & $11.368 \%$ & $17.407 \%$ & $20.403 \%$ & $28.800 \%$ \\
\hline 17 & $12.946 \%$ & $19.156 \%$ & $22.128 \%$ & $31.407 \%$ & 80 & $11.298 \%$ & $17.266 \%$ & $20.329 \%$ & $28.577 \%$ \\
\hline 18 & $12.842 \%$ & $19.079 \%$ & $22.010 \%$ & $31.294 \%$ & 90 & $11.243 \%$ & $17.154 \%$ & $20.272 \%$ & $28.343 \%$ \\
\hline 19 & $12.744 \%$ & $19.000 \%$ & $21.897 \%$ & $31.182 \%$ & 100 & $11.201 \%$ & $17.056 \%$ & $20.228 \%$ & $28.178 \%$ \\
\hline 20 & $12.655 \%$ & $18.924 \%$ & $21.800 \%$ & $31.088 \%$ & 110 & $11.168 \%$ & $16.973 \%$ & $20.189 \%$ & $28.057 \%$ \\
\hline 21 & $12.573 \%$ & $18.841 \%$ & $21.707 \%$ & $30.982 \%$ & 120 & $11.139 \%$ & $16.902 \%$ & $20.156 \%$ & $27.945 \%$ \\
\hline 22 & $12.499 \%$ & $18.786 \%$ & $21.624 \%$ & $30.907 \%$ & 130 & $11.113 \%$ & $16.831 \%$ & $20.131 \%$ & $27.871 \%$ \\
\hline 23 & $12.431 \%$ & $18.724 \%$ & $21.549 \%$ & $30.827 \%$ & 140 & $11.092 \%$ & $16.782 \%$ & $20.110 \%$ & $27.800 \%$ \\
\hline 24 & $12.369 \%$ & $18.665 \%$ & $21.479 \%$ & $30.707 \%$ & 150 & $11.073 \%$ & $16.727 \%$ & $20.090 \%$ & $27.710 \%$ \\
\hline 25 & $12.310 \%$ & $18.617 \%$ & $21.417 \%$ & $30.643 \%$ & 160 & $11.058 \%$ & $16.681 \%$ & $20.071 \%$ & $27.634 \%$ \\
\hline 26 & $12.257 \%$ & $18.568 \%$ & $21.360 \%$ & $30.567 \%$ & 170 & $11.044 \%$ & $16.644 \%$ & $20.058 \%$ & $27.581 \%$ \\
\hline 27 & $12.205 \%$ & $18.523 \%$ & $21.307 \%$ & $30.513 \%$ & 180 & $11.032 \%$ & $16.609 \%$ & $20.046 \%$ & $27.518 \%$ \\
\hline 28 & $12.160 \%$ & $18.480 \%$ & $21.255 \%$ & $30.469 \%$ & 190 & $11.021 \%$ & $16.578 \%$ & $20.032 \%$ & $27.472 \%$ \\
\hline 29 & $12.115 \%$ & $18.439 \%$ & $21.207 \%$ & $30.434 \%$ & 200 & $11.011 \%$ & $16.547 \%$ & $20.023 \%$ & $27.432 \%$ \\
\hline 30 & $12.077 \%$ & $18.396 \%$ & $21.160 \%$ & $30.357 \%$ & 210 & $11.001 \%$ & $16.519 \%$ & $20.012 \%$ & $27.383 \%$ \\
\hline 31 & $12.036 \%$ & $18.357 \%$ & $21.118 \%$ & $30.282 \%$ & 220 & $10.992 \%$ & $16.496 \%$ & $20.001 \%$ & $27.341 \%$ \\
\hline 32 & $11.999 \%$ & $18.313 \%$ & $21.081 \%$ & $30.241 \%$ & 230 & $10.985 \%$ & $16.472 \%$ & $19.993 \%$ & $27.309 \%$ \\
\hline 33 & $11.964 \%$ & $18.274 \%$ & $21.044 \%$ & $30.177 \%$ & 240 & $10.978 \%$ & $16.448 \%$ & $19.986 \%$ & $27.280 \%$ \\
\hline 34 & $11.931 \%$ & $18.241 \%$ & $21.006 \%$ & $30.123 \%$ & 250 & $10.972 \%$ & $16.428 \%$ & $19.980 \%$ & $27.252 \%$ \\
\hline 35 & $11.900 \%$ & $18.206 \%$ & $20.976 \%$ & $30.080 \%$ & $\vdots$ & $\vdots$ & $\vdots$ & $\vdots$ & $\vdots$ \\
\hline 36 & $11.873 \%$ & $18.171 \%$ & $20.947 \%$ & $30.038 \%$ & 498 & $10.813 \%$ & $15.904 \%$ & $19.814 \%$ & $26.498 \%$ \\
\hline
\end{tabular}




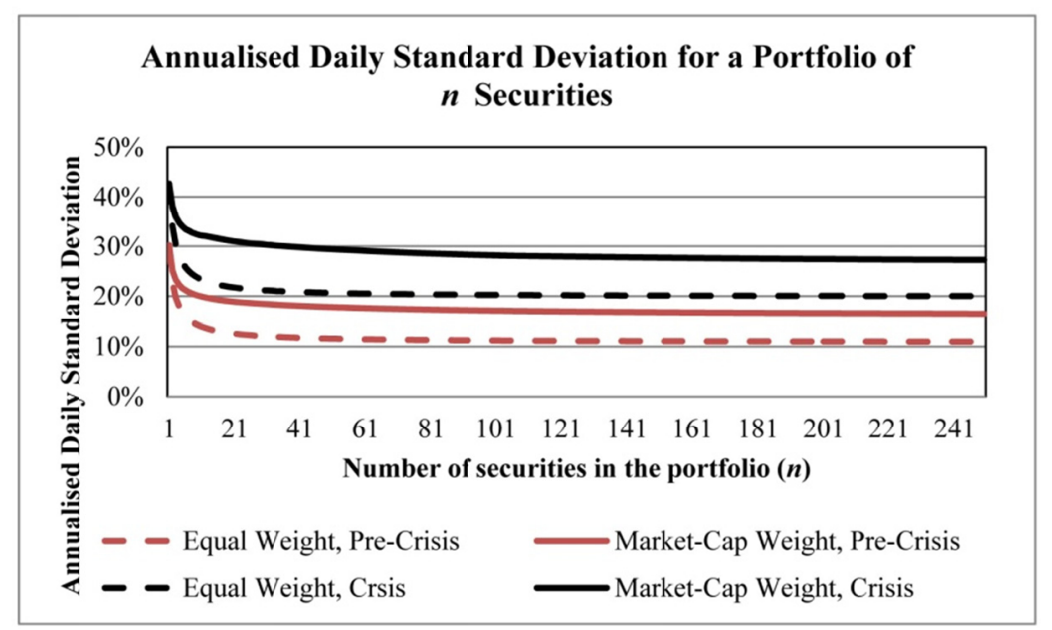

Figure 1. Annualised Daily Standard Deviation of Returns vs. $n$

As is apparent from both the Figure 1 and Table 1, portfolio standard deviation decreases monotonically with an increase in $n$. Further, portfolio standard deviation was larger during the crisis vis-à-vis the pre-crisis period for both the weighting methodologies, and market-cap weighting led to larger standard deviations than equal weighting. Such results are consistent with present literature which investigates recent equity market behavior during the last decade (Hjalmarsson \& Manchev, 2012; Abhyankar \& Ho, 2007).

Moving on to the other summary statistic central to the inputs of our absolute diversification benefit and cost-benefit analysis, the geometric mean return of the portfolios converged to the population geometric mean returns as stated in the table 2. The figures represent the expected geometric mean return of a portfolio of size $n$, for all $n$ ranging from 1 to 250 .

Table 2. Annualised Daily Geometric Mean Returns

\begin{tabular}{lcc}
\hline & $\begin{array}{c}\text { Pre-Crisis Period } \\
\text { 1 July 2002 to 30 June 2007 }\end{array}$ & $\begin{array}{c}\text { Crisis Period } \\
\text { 1 July 2007 to 30 June 2012 }\end{array}$ \\
\hline Equally Weighted Portfolio & $18.488 \%$ & $2.568 \%$ \\
Market-Cap Weighted Portfolio & $13.021 \%$ & $2.274 \%$ \\
\hline
\end{tabular}

These return and standard deviation data are utilised as set out in the methodology to derive the results in sections 4.3 and 4.4 below.

\subsection{Absolute Benefits of Diversification}

Table 3. Test Statistic from Levene's Test on the Homogenity of Variances

\begin{tabular}{ccccc}
\hline \multirow{2}{*}{ Run (Note 1) } & \multicolumn{4}{c}{ Test Statistic from Levene's Test on the Homogeneity of Variances (Note 2) } \\
\cline { 2 - 5 } & $\begin{array}{c}\text { Equally Weighted } \\
{[\mathbf{0 2}-\mathbf{0 7 ]}}\end{array}$ & $\begin{array}{c}\text { Market Capitalisation Weighted [02- 07] } \\
\text { Equally Weighted } \\
{[\mathbf{0 7}-\mathbf{1 2}]}\end{array}$ & $\begin{array}{c}\text { Market capitalisation Weighted } \\
\text { [07- 12] }\end{array}$ \\
\hline 1 & 197.264 & 131.110 & 248.069 & 107.892 \\
2 & 105.538 & 73.192 & 113.915 & 32.825 \\
3 & 51.107 & 30.620 & 61.738 & 14.900 \\
4 & 29.859 & 18.349 & 47.718 & 10.836 \\
5 & 31.020 & 10.462 & 25.842 & 7.139 \\
6 & 16.940 & 4.991 & 26.674 & 4.513 \\
7 & 15.848 & 5.667 & 17.475 & 3.571 \\
8 & 11.889 & 5.772 & 14.273 & 1.842 \\
9 & 9.891 & 2.658 & 13.662 & 1.891 \\
10 & 7.458 & 2.339 & 7.256 & 0.551
\end{tabular}




\begin{tabular}{|c|c|c|c|c|}
\hline 11 & 5.372 & 2.010 & 7.773 & 0.439 \\
\hline 12 & 5.228 & 0.967 & 6.001 & 0.483 \\
\hline 13 & 6.204 & 1.910 & 5.808 & 0.625 \\
\hline 14 & 3.285 & 0.706 & 3.934 & 0.381 \\
\hline 15 & 4.218 & 0.960 & 5.093 & 0.531 \\
\hline 16 & 3.170 & 0.638 & 3.312 & 0.957 \\
\hline 17 & 2.140 & 0.547 & 3.003 & 0.218 \\
\hline 18 & 2.665 & 0.879 & 3.155 & 0.341 \\
\hline 19 & 2.514 & 0.472 & 3.266 & 0.262 \\
\hline 20 & 1.789 & 0.340 & 2.971 & 0.483 \\
\hline 21 & 2.014 & 0.756 & 2.528 & 0.177 \\
\hline 22 & 1.647 & 0.440 & 2.632 & 0.188 \\
\hline 23 & 1.975 & 0.296 & 2.435 & 0.324 \\
\hline 24 & 1.783 & 1.038 & 1.409 & 0.178 \\
\hline 25 & 1.807 & 0.384 & 1.306 & 0.096 \\
\hline 26 & 1.281 & 0.809 & 1.969 & 0.081 \\
\hline 27 & 1.327 & 0.486 & 1.866 & 0.144 \\
\hline 28 & 0.693 & 0.253 & 1.236 & 0.189 \\
\hline 29 & 1.027 & 0.520 & 0.708 & 0.358 \\
\hline 30 & 1.022 & 0.245 & 1.198 & 0.298 \\
\hline 31 & 0.941 & 0.298 & 1.262 & 0.019 \\
\hline 32 & 1.140 & 0.450 & 1.150 & 0.142 \\
\hline 33 & 0.563 & 0.452 & 1.074 & 0.161 \\
\hline 34 & 0.678 & 0.426 & 0.768 & 0.134 \\
\hline 35 & 0.622 & 0.381 & 0.688 & 0.122 \\
\hline 36 & 0.694 & 0.239 & 0.806 & 0.043 \\
\hline 37 & 0.609 & 0.168 & 1.330 & 0.177 \\
\hline 38 & 0.678 & 0.239 & 1.107 & 0.165 \\
\hline 39 & 0.768 & 0.356 & 1.144 & 0.253 \\
\hline 40 & 0.516 & 0.196 & 0.868 & 0.141 \\
\hline 41 & 0.523 & 0.446 & 0.731 & 0.071 \\
\hline 42 & 0.779 & 0.387 & 0.557 & 0.151 \\
\hline 43 & 0.604 & 0.367 & 0.531 & 0.036 \\
\hline 44 & 0.554 & 0.389 & 0.899 & 0.290 \\
\hline 45 & 0.506 & 0.174 & 0.588 & 0.086 \\
\hline 46 & 0.823 & 0.286 & 0.386 & 0.049 \\
\hline 47 & 0.326 & 0.438 & 0.310 & 0.099 \\
\hline 48 & 0.621 & 0.573 & 0.677 & 0.072 \\
\hline 49 & 0.308 & 0.167 & 0.592 & 0.189 \\
\hline 50 & 0.586 & 0.497 & 0.306 & 0.083 \\
\hline$\vdots$ & $\vdots$ & $\vdots$ & $\vdots$ & $\vdots$ \\
\hline 246 & 0.011 & 0.014 & 0.012 & 0.021 \\
\hline 247 & 0.021 & 0.010 & 0.007 & 0.045 \\
\hline 248 & 0.007 & 0.029 & 0.013 & 0.018 \\
\hline 249 & 0.024 & 0.038 & 0.026 & 0.001 \\
\hline
\end{tabular}

Table 3 shows the results from Levene's test. Levene's test compares 2 samples and tests for equality of variances. The benefit of Levene's test compared to other tests on the equality of variances such as the F-test is that it is robust for samples that are not normally distributed. From a diversification perspective, this section shows whether further successive increases in portfolio size results in a statistically significant change in variance. For equally weighted portfolios, increasing the portfolio size from 33 to 34 during the 'pre-crisis' period and increasing the portfolio size from 41 to 42 during the 'crisis period' no longer leads to a change in risk that is statistically significant. For market capitalisation weighted portfolios, increasing the portfolio size from 16 to 17 during the 'pre-crisis' period and increasing the portfolio size from 10 to 11 during the 'crisis period' no longer leads to a change in risk that is statistically significant. From the results, we also see that the market 
capitalisation weighted portfolios demonstrated less benefit from diversification compared to the equally weighted portfolios over both time periods.

\subsection{Cost-benefit Analysis}

The table 4 below displays the benefit of full diversification for both the pre-crisis and crisis period for an equally weighted and market capitalisation weighted portfolio of $n$ equities, with $n$ ranging from 1 to 250 and $n=$ 498.

Table 4. Benefit of Full Diversification (Annualised \% Return)

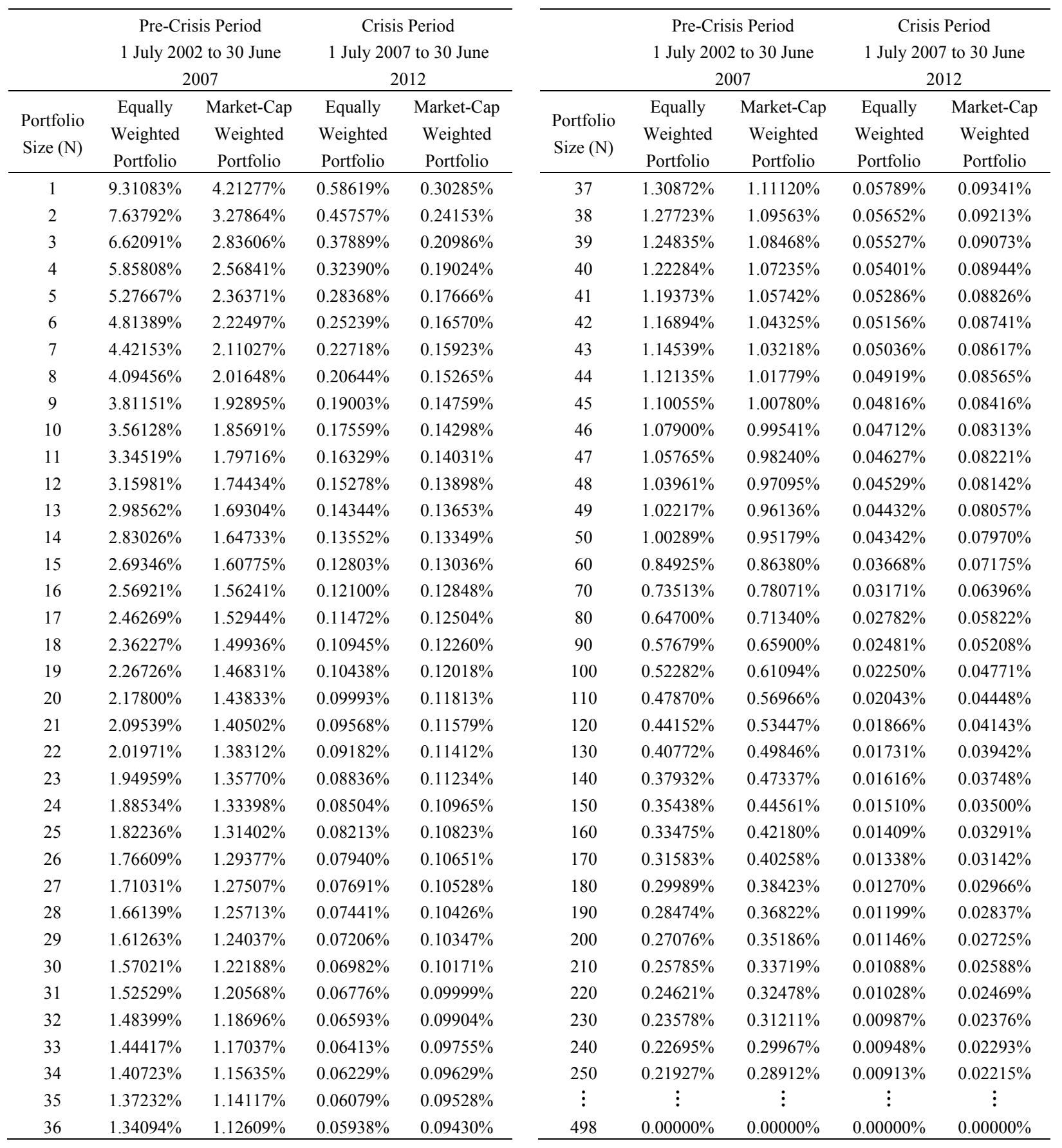

Data from Table 4 is also presented in Figure 2 and Figure 3. Figure 2 shows how the benefit of full diversification decreases monotonically with $n$, and it was markedly lower during the crisis period as is 
consistent with the findings of the Levene's Test. Figure 3 is a rescaled version of Figure 2 that includes a horizontal line that represents the cost of diversification, equal to $0.40 \%$ as set out in the section 3.3.2.

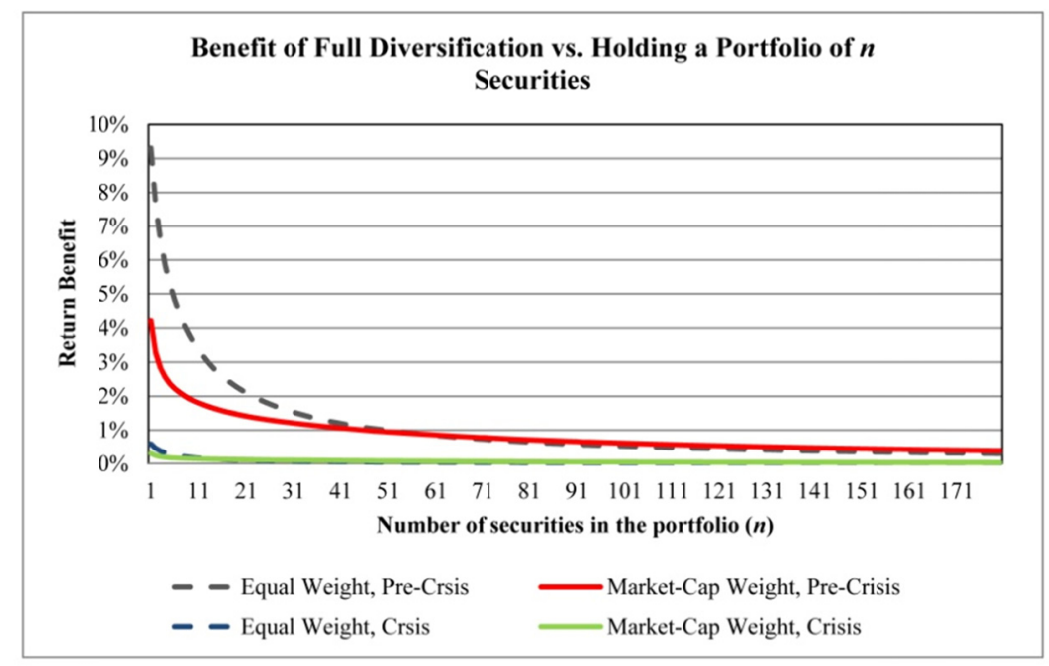

Figure 2. Benefit of Full Diversification (Annualised \% Return) vs. N

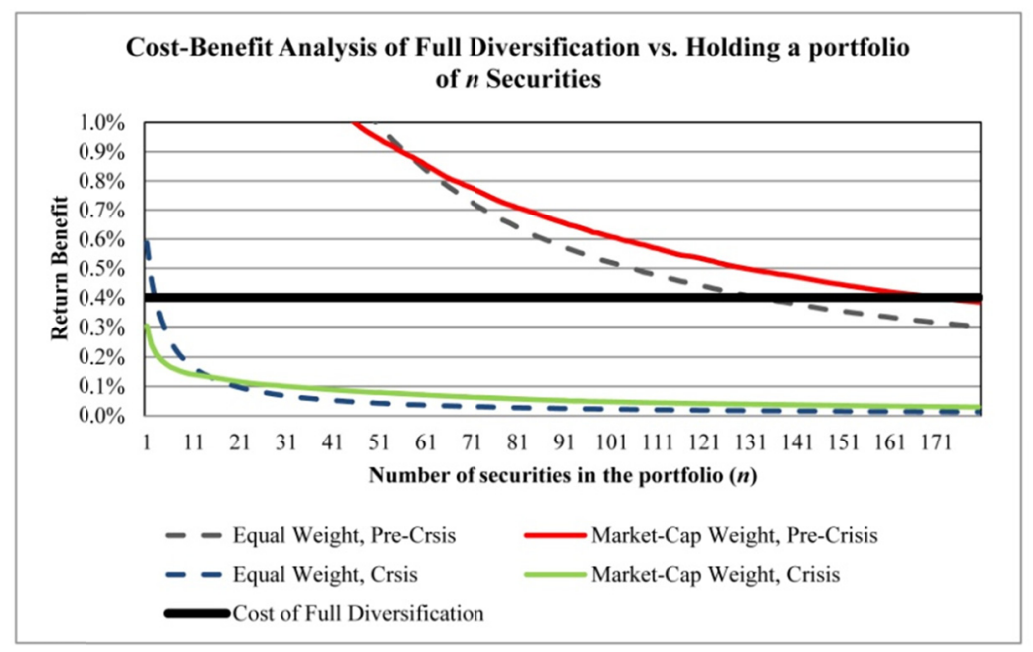

Figure 3. Cost-Benefit Analysis of Full Diversification (Annualised \% Return) vs. N

As seen from Figure 2 and Figure 3, the marginal cost of diversification exceeds the marginal benefit for $n=133$ and $n=172$ for an equally weighted and market capitalisation weighted portfolio respectively during the pre-crisis period. On the other hand, the crisis period saw starkly dissimilar results, namely $n=3$ and $n=1$ for an equally weighted and market capitalisation weighted portfolio respectively.

\section{Discussion}

\subsection{Time Period}

The crisis period showed markedly lower absolute benefits via the cost-benefit analysis due to diversification compared to the pre-crisis period. The statistical significance of such a result is strengthened by our results from the Levene's Test - the relative change in diversification benefit was significant at relatively high values of $n$.

Such adverse sensitivity of absolute diversification benefits to the trading and economic regime is consistent with the empirical findings of present literature and the prevalent belief that correlations increase in periods of market stress and left-tail events (Hwang \& Min, 2012). This leads to important implications for market practitioners, chiefly being that equity diversification benefits and the asset allocation decision is highly sensitive 
to ex-ante predictions of trading regime. Such sensitivity should be recognised in the cost-benefit analysis of any portfolio construction process, and while beyond the scope of this study, we postulate that the said margin of error can be lessened if the investor includes international equity or other asset classes that could attenuate the rise in correlation between portfolio constituents during market stress and tail events. Also beyond this study, an interesting topic for investigation is how the benefits of diversification have evolved with time and how they might evolve in the future. Such will build on studies such as that of Christoffersen et al. (2010), which considers the evolution of international diversification benefits; there is scope, however, for studies to be performed on the national level and across asset classes.

\subsection{Absolute vs. Practical Benefits}

In our study, the Levene's Test showed how increasing the number of securities $n$ in a portfolio led to statistically significant relative gains in diversification benefit. Such results should be interpreted with caution, however. Any form of practical portfolio construction would not be based upon the statistical significance of adding the marginal security, as set out in the seminal Evans and Archer (1968) and Benjelloun (2010), but on a cost-benefit analysis similar to that which we have performed in this paper.

To stress on the importance of utilising such a cost-benefit analysis in practical applications, contrary to the Levene's test, the cost-benefit analysis suggested a diversification extent far short of that suggested by Levene's Test during the crisis period. This does not come as a surprise given the highly correlated trading observed during the period, and hence the lesson learnt is that practitioners should be weary of outputs from models based on relative benefits of diversification, as opposed to ones that weigh the absolute benefits and costs of diversification.

\subsection{Alternative Weighting Strategies}

As is apparent from Figure 2 and Figure 3, the benefit of diversification for a market capitalization weighted portfolio is lower than that for equally weighted portfolios for small values of $n$, but becomes higher for larger values of $n$. Based on these observations, we can only conclude that the strategies considered are not systematically different in their relation to diversification benefit. The profile of benefits of diversification for equally weighted and market-cap weighted portfolios differ. The choice of weighting strategy in practical applications at the cost-benefit equivalence point is determined by whether the crossing over of the pair of lines in each period occurs above or below the cost benchmark. From this, we know that the choice between investing in a market capitalization weighted portfolio and an equally weighted portfolio is highly sensitive to the trading regime in consideration. Explaining the factors which affect the relative position between the cost benchmark and the crossover point, however, is beyond the scope of this paper, though we postulate that the cause of the crossover could be due to diversification benefits being insignificant for a small portfolio that is heavily tilted towards a few large cap stocks, and is significant only when the portfolio is larger, more evenly weighted and increasingly granular. There is certainly scope for further econometric analysis in this topic of study.

\section{Conclusion}

In this study, we investigate the benefits of diversification using alternative weighting strategies. We simulate random portfolios of different sizes and analyse the volatility of these simulated portfolios to determine the risk reduction benefits of holding a larger number of securities. These portfolios were constructed on an equally weighted and market capitalisation weighted basis which we contend is a better approach to obtain more realistic results. We investigate the absolute benefits of risk reduction using Levene's Test and the practical benefits by performing an explicit cost-benefit comparison. We conduct this analysis on the UK equity market over the 'pre-crisis' and 'crisis' period and find that the absolute benefits of diversification for a market capitalisation weighted portfolio are smaller than the absolute benefits of diversification for an equally-weighted portfolio. When we investigate the benefits to diversification over the 2 time periods, we find that the benefits to diversification of an equally weighted portfolio are greater in the 'crisis' than 'pre-crisis' period, but when we look at it from a practical perspective the benefits fall dramatically and the results are reversed. This lends weight to the need to consider not just the absolute benefits but also the achievable benefits of diversification. When comparing the benefits of market capitalisation weighted and equally weighted portfolios, we note that the benefits of diversification tend to be greater for an equally weighted portfolio for small portfolios but that a crossover occurs as the size of the portfolio increases.

While analysing the causal factors that lead to differences in values of $n$ between the two periods and weighting methodologies is not within the scope of this paper, there was evidence during the investigation that suggested why the model might have recommended virtually zero diversification during the crisis period. Most significantly, the geometric mean annual return of the $m$-security population portfolio, at $2.57 \%$, stood just 1.73 
times above the annual risk free rate of $1.48 \%$. The poor market returns sharply reduced the benefit of diversification, given the accompanying cost - the average stock gave a meager if not negative return. Further still, it was apparent from the raw data and summary statistics (which showed that returns were weaker $-2.27 \%$ vs. $2.57 \%$ - and standard deviation higher $-26.50 \%$ vs. $19.81 \%$ - for the market-cap weighted portfolio as opposed to the equally weighted portfolio) that large market capitalisation stocks underperformed the index while having higher standard deviations. Such would further decrease the benefit of diversifying into the index, given that these poor-performing large cap stocks will be over-weighted in the portfolio. Lastly, we hypothesise that the heightened correlation between large-cap financials during the global financial crisis, exacerbated by their sizeable presence in the index and their overweighting in a portfolio would have further reduced the marginal benefit of diversification for each $n$-security portfolio. Further investigation will be required to determine if this is the case.

\section{References}

Abhyankar, A., \& Ho, K. Y. (2007). Long-horizon event studies and event firm portfolio weights: evidence from U.K. rights issues re-visited. International Review of Financial Analysis, 16(1), 61-80. http://dx.doi.org/10.1016/j.irfa.2005.02.001

Benjelloun, H. (2010). Evans and Archer - Forty Years Later. Investment Management and Financial Innovations, 7(1), 98-104.

Bird, R., \& Tippet, M. (1986). Naive diversification and portfolio risk-A Note. Management Science, 32(2), 244-251. http://dx.doi.org/10.1287/mnsc.32.2.244

Box, G. (1953). Non-normality and tests on variances. Biometrika, 40(3), 318-335. http://dx.doi.org/10.2307/2333350

Brown, M., \& Forsythe, A. (1974). Robust tests for equality of variances. Journal of the American Statistical Association, 69, 364-367. http://dx.doi.org/10.2307/2285659

Christoffersen, P., Errunza, V., Jacobs, K., \& Jin, X. (2010). Is the potential for international diversification disappearing. http://dx.doi.org/10.2139/ssrn.1573345

Damodaran, A. (2010). Equity risk premiums: determinants, estimation and implications - a post-crisis update. Financial Markets, Institutions \& Instruments, 18(5), 289-370.

Elton, E., \& Gruber, M. (1977). Risk reduction and portfolio size: an analytical solution. Journal of Business, 50(4), 415-437. http://dx.doi.org/10.1086/295964

Evans, J., \& Archer, S. (1968). Diversification and the reduction of dispersion: an empirical analysis. Journal of Finance, 23(5), 761-767. http://dx.doi.org/10.2307/2325905

Gastwirth, J., Gel, Y., \& Miao, W. (2009). The impact of Levene's test of equality of variances on statistical theory and practice. Statistical Science, 24(3), 343-360. http://dx.doi.org/10.1214/09-STS301

Gupta, G. S., \& Khoon, C. H. (2001). How many securities make a diversified portfolio in KLSE stocks. Asian Academy of Management Journal, 6(1), 63-79.

Hjalmarsson, E., \& Manchev, P. (2012). Characteristic-based mean-variance portfolio choice. Journal of Banking \& Finance, 36(5), 1392-1401.

Huang, W., Eun, C., \& Lai, S. (2006). International diversification with large- and small-cap stocks. Journal of Financial and Quantitative Analysis, 43(2), 489-524. http://dx.doi.org/10.1016/j.ribaf.2011.03.003

Hwang, Y, \& Min, H. (2012). Dynamic correlation analysis of US financial crisis and contagion: evidence from four OECD countries. Applied Financial Economics, 22(24), 2063-2074.

Lai, M. S., \& Seiler, M. J. (2001). Is your portfolio overweighted? Know when to say when, Journal of Wealth Management, 3(4), 19-28. http://dx.doi.org/10.3905/jwm.2001.320391

Lee, S. L. (2005). The marginal benefit of diversification in commercial real estate portfolios. Working Papers in Real Estate \& Planning 04/05.

Levene, H. (1960). Robust tests for equality of variances. In I. Olkin (Ed.), Contributions to Probability and Statistics, 278-292. Palo Alto, California: Stanford University Press.

Lim, S., \& Loh, Y. (1996). A comparison of tests of equality of variances. Computational Statistical \& Data Analysis, 22(3), 287-301. http://dx.doi.org/10.1016/0167-9473(95)00054-2

Markowski, C., \& Markowski, E. (1990). Conditions for the effectiveness of a preliminary test of variance. The 
American Statistician, 44(4), 322-326. http://dx.doi.org/10.2307/2684360

Mukherji, S. (2011). The capital asset pricing model's risk-free rate. The International Journal of Business and Finance Research, 5(2), 75-83.

Newbould, G. D., \& Poon, P. S. (1993). Portfolio risk, portfolio performance, and the individual investor, Journal of Investing, 5(2), 72-78. http://dx.doi.org/10.3905/joi.5.2.72

Newbould, G. D., \& Poon, P. S. (1993). The minimum number of stocks needed for diversification. Financial Practice and Education, 3, 85-87.

Snedecor, G. W., \& Cochran, W. G. (1976). Statistical Methods (6th ed.). Ames, IA: Iowa State University Press. http://dx.doi.org/10.1097/00010694-195702000-00023

Statman, M. (1987). How many stocks make a diversified portfolio. Journal of Financial and Quantitative Analysis, 22(3), 353-363. http://dx.doi.org/10.2307/2330969

Statman, M. (2004). The diversification puzzle. Financial Analysts Journal, 60(4), 44-53. http://dx.doi.org/10.2469/faj.v60.n4.2636

\section{Notes}

Note 1 . This refers to the $\mathrm{W}$ statistic that tests the equality of variances between successive securities. Run 1 , for example, tests the equality of variances between a portfolio of 1 security and a portfolio of 2 securities.

Note 2. Critical Value of F-Statistic for this test is 0.8323066. 